\title{
Epidemiology of Osteoporosis in Patients with Type 1 Diabetes Mellitus
}

\author{
Khalid S Aljabri ${ }^{1 *}$, Samia A Bokhari ${ }^{2}$, Muneera A Alshareef ${ }^{1}$, Patan M Khan ${ }^{\mathbf{1}}$ and Bandari K Aljabri MS ${ }^{\mathbf{2}}$ \\ ${ }^{1}$ Department of Endocrinology, King Fahad Armed Forces Hospital, Jeddah, Kingdom of Saudi Arabia \\ ${ }^{2}$ College of medicie, Um Al Qura University, Saudi Arabia
}

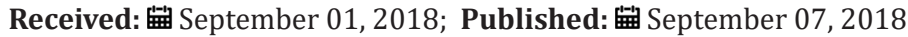

*Corresponding author: Khalid S Aljabri, Department of Endocrinology, King Fahad Armed Forces Hospital, Jeddah, Kingdom of Saudi Arabia

\section{Abstract}

Background and Objective: The incidence of type 1 diabetes is increasing. Osteoporosis has become an alarming health problem throughout the entire world. The aim of this study were to estimate the epidemiology of osteoporosisamong Saudi patients with T1DM, living in the western province, attending the diabetes centre at King Fahd Armed Forces Hospital, Jeddah, KSA.

Methods: Eligible patients were older than 12 years old, had T1DM . All patients were recruited from the population of the Diabetic Centre at King Fahad Armed Forces Hospital. Eligible patients met with investigators for a complete history and physical examination, to have baseline laboratory assessments including glycosylated haemoglobin (HbA1c). HbA1c was expressed as percentage and measured using the high-performance liquid chromatography. BMD in the current study was measured using The Lunar Achilles (In Sight, GE Healthcare, USA), which is a proven bone ultrasonometer to avoid exposing the children to unnecessarily ionizing radiation. All measurements were converted to Z-scores using a data bank for age-matched speed of sound values supplied by the manufacturer. We excluded patients with a history of fractures of less than 1 year and those with associated bone/joint problems, liver disease or patients on long-term steroid therapy.

Main results: 137 patients completed the study. There were 60 (44\%) male and 77 (56\%) were female with mean age $19.1 \pm 4.9$. Osteoporosis was found in 53 of cases (38.7\%) of patients. There were $23(43.4 \%)$ male and $30(56.6 \%)$ were female giving a female to male ratio 1.3:1. Osteoporosis was found in 53 of cases (38.7\%) of patients. Baseline characteristics are shown in Table 1. Patients with osteoporosis were significantly younger, longer diabetes duration and have higher HbA1c than patients without osteoporosis. Osteoporosis was higher in females than male and was seen more in cases with HbA1c $>9.0$ as compared to HbA1c groups of $<8.0$ and 8-9, (Figures $1 \& 2$ ). Cases with longer diabetes duration ( $\geq 6$ years) have nonsignificant more frequent osteoporosis than cases with diabetes duration $<6$ years, $34 \%$ vs. $66 \%$ respectively, $p=0.4$. There were no significant differences between genders and frequency of osteoporosis in relation to diabetes duration.

Conclusion: Our findings demonstrate lower BMD in young women with type 1 diabetes. Although bone density testing is not routinely performed in young women, these data suggest that screening may be important in young women with type 1 diabetes. In addition, these women should be counseled regarding lifestyle interventions that may improve bone health, including adequate intake of calcium and vitamin D, and exercise.

\section{Introduction}

Type 1 diabetes mellitus (T1DM) results from a cellularmediated autoimmune destruction of the $\beta$-cells of the pancreas [1]. T1DM accounts for about $10 \%$ of all diabetes, affecting approximately 1.4 million people in the U.S, and 10-20 million globally [2]. The prevalence of T1DM was $0.193 \%$ in the Saudi males and $0.237 \%$ in the Saudi females [3] Osteoporosis has become an alarming health problem throughout the entire world, and approximately 200 million people in the world are threatened by this deleterious disease [4,5]. Osteoporosis is often described as a silent disease because it is typically asymptomatic until a fracture occurs [6]. Along with increased risk of complications including retinopathy, nephropathy, neuropathy, and cardiovascular events, 
adults with type 1 diabetes have decreased bone mineral density (BMD) compared with control subjects [7,8]. In fact, osteoporosis is the most significant metabolic bone disease in individuals with diabetes [9]. Patients with diabetes are at risk for osteoporosis and its complications, including hip fracture [10]. Recent studies demonstrate that diabetes is associated with alterations in bone health in children and adolescents [6,11-13]. These observations suggest that adverse effects on bone health may occur early after the diabetes diagnosis. This study was undertaken to estimate the epidemiology of osteoporosis among Saudi patients with T1DM, living in the western province, attending the diabetes centre at King Fahd Armed Forces Hospital, Jeddah, KSA.

\section{Methods}

Eligible patients were older than 12 years old, had T1DM. All patients were recruited from the population of the Diabetic Centre at King Fahad Armed Forces Hospital. All the patients gave their or their guardian informed consent prior to their inclusion. Eligible patients met with investigators for a complete history and physical examination, to have baseline laboratory assessments including glycosylated hemglobin (HbA1c). HbA1c was expressed as percentage and measured using the high performance liquid chromatography. BMD in the current study was measured using The Lunar Achilles (Insight, GE Healthcare, USA), which is a proven bone ultrasonometer to avoid exposing the children to unnecessarily ionizing radiation. All measurements were converted to Z-scores using a data bank for age-matched speed of sound values supplied by the manufacturer. We excluded patients with a history of fractures of less than 1 year and those with associated bone/joint problems, liver disease or patients on long-term steroid therapy.

\section{Statistical Analysis}

Univariate analysis of baseline and follow up demography and clinical laboratory endpoints were accomplished using unpaired t-test where appropriate. Chi square $\left(\mathrm{X}^{2}\right)$ test were used for categorical data comparison. All statistical analyses were performed using SPSS Version 22.0. All P values were based on two-sided tests. The difference between groups was considered significant when $\mathrm{P}<0.05$.

\section{Results}

Baseline characteristics are shown in table 1. 137 patients completed the study. There were 60 (44\%) male and 77 (56\%) were female with mean age $19.1 \pm 4.9$ (minimum=12, maximum = 37) years. Osteoporosis was found in 53 of cases $(38.7 \%)$ of patients. There were 23 (43.4\%) male and 30 (56.6\%) were female giving a female to male ratio 1.3:1. Patients with osteoporosis were significantly younger, longer diabetes duration and have higher HbA1c than patients without osteoporosis. Osteoporosis was higher in females than male and was seen more in cases with $\mathrm{HbA1c}$ $>9.0$ as compared to HbA1c groups of $<8.0$ and 8-9, (Figures $1 \& 2$ ). Cases with longer diabetes duration ( $\geq 6$ years) have nonsignificant more frequent osteoporosis than cases with diabetes duration $<6$ years, $34 \%$ vs. $66 \%$ respectively, $\mathrm{p}=0.4$. There were no significant differences between genders and frequency of osteoporosis in relation to diabetes duration (Figure 3).

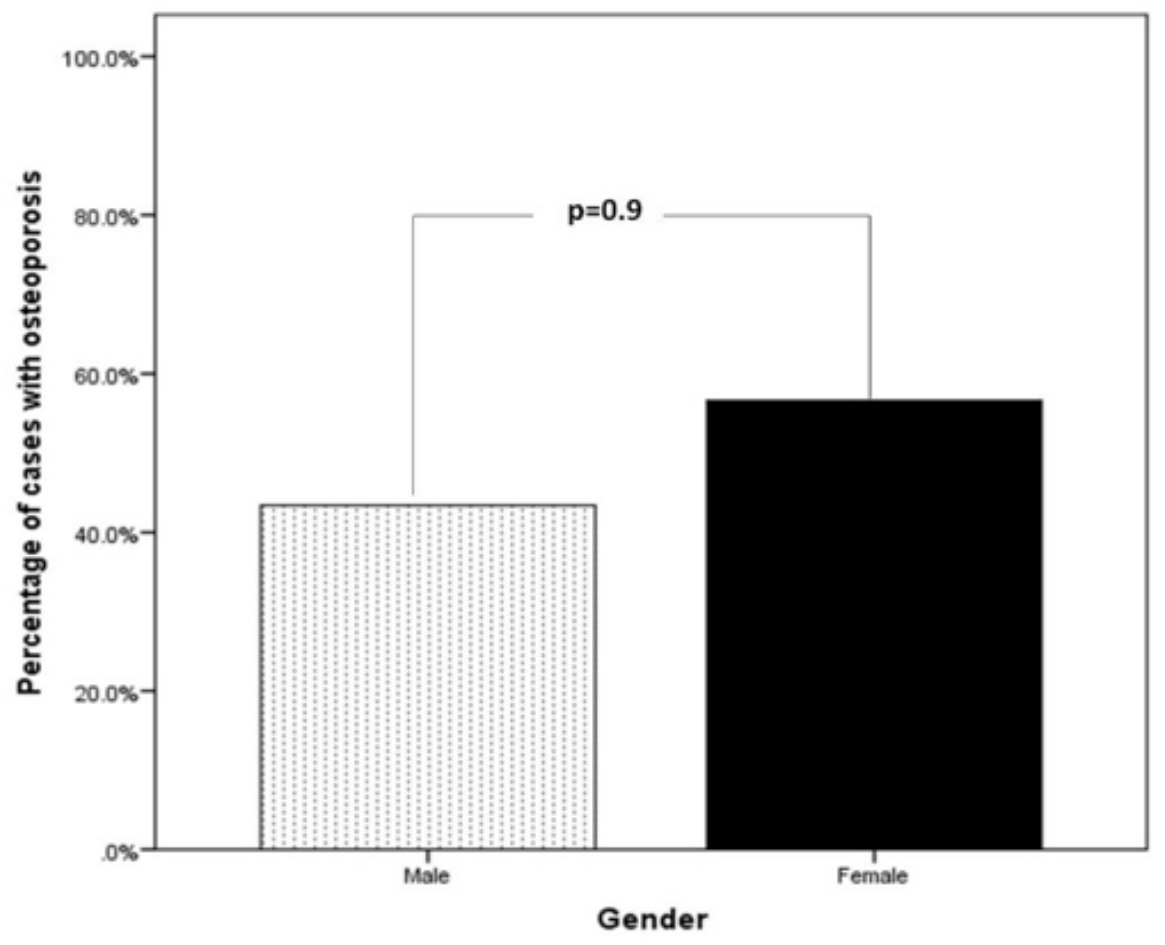

Figure 1: Percentage of cases of type 1 diabetes mellitus associated with osteoporosis in relation to gender. 


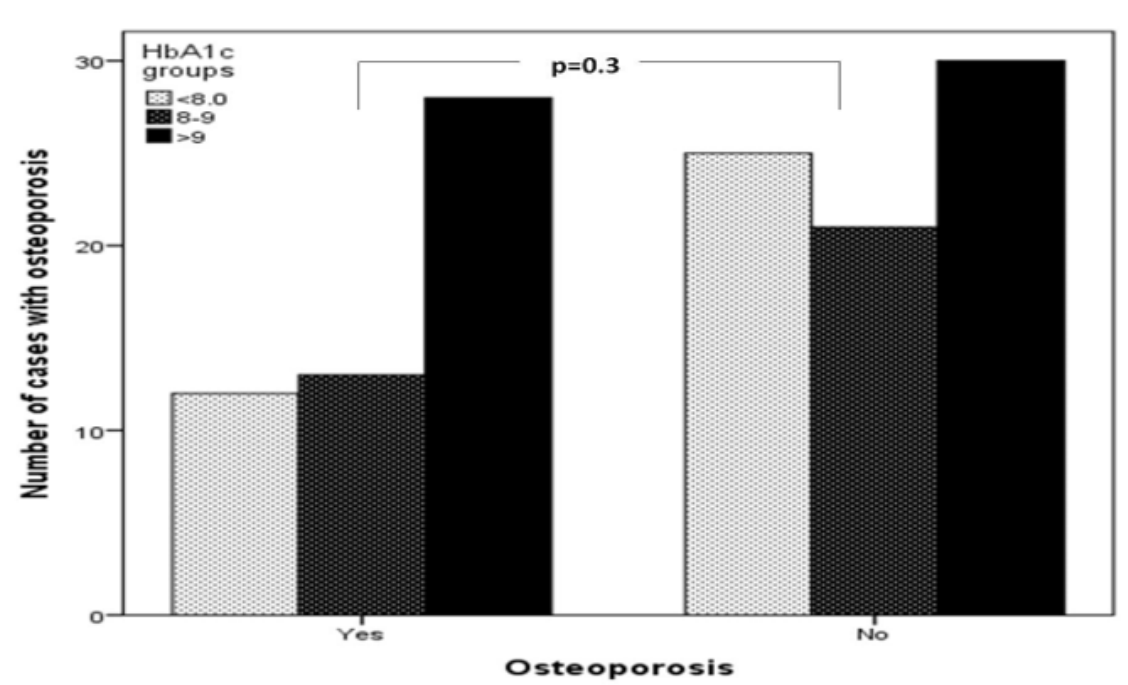

Figure 2: Number of cases of type 1 diabetes mellitus associated with osteoporosis in relation to HbA1c groups.

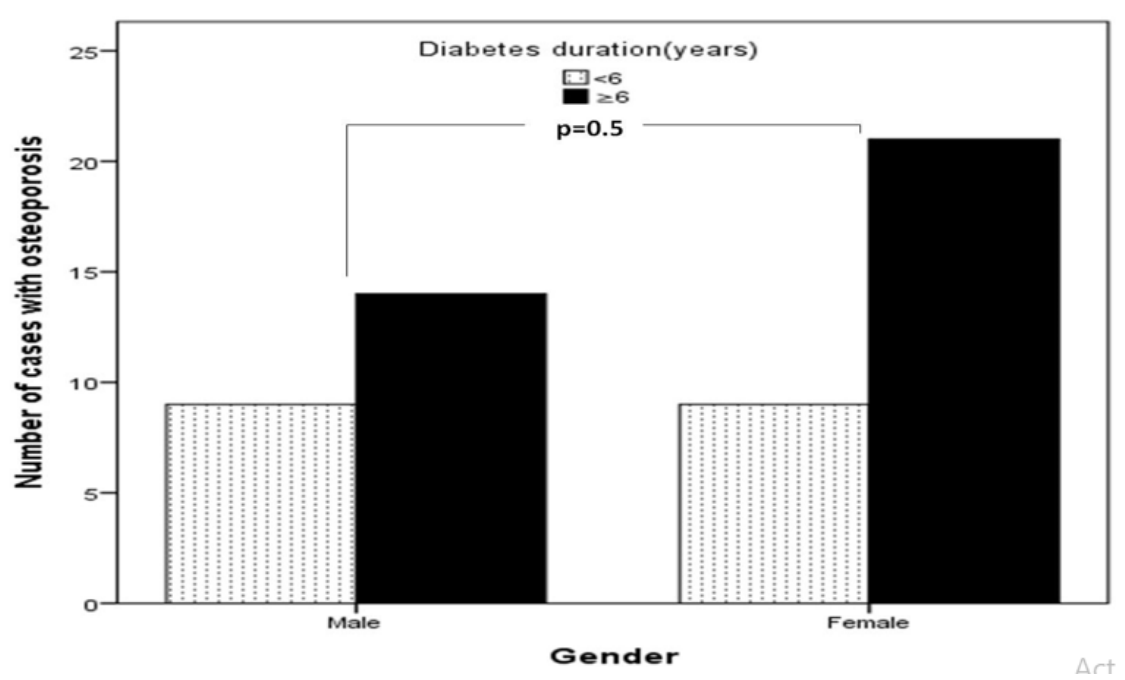

Figure 3: Number of cases with type 1 diabetes mellitus associated with osteoporosis in relation to diabetes duration (years).

\section{Discussion}

In agreement with many studies, the present study has confirmed that osteoporosis is associated with T1DM.

[14-16] However, it was unclear until recently whether this translated into increased fracture rates. A number of studies have shown that poor glycemic control in patients with T1DM is associated with osteopenia and osteoporosis $[17,18]$. Poor glycemic control for long period of time can result into microvascular complications and can aggravate the loss of bone density by various mechanisms. Nephropathy can predispose patients with diabetes to hypercalciuria and can alter the vitamin D metabolism causing vitamin D deficiency $[19,20]$. Hyperglycemia may lead to an increased loss of calcium in the urine, which can in turn cause a negative calcium balance [21]. Furthermore, use of loop diuretics in patients with diabetic nephropathy is associated with low bone mineral density (BMD) as these drugs cause the renal excretion of calcium [22]. Insulin-like growth factors and other cytokines may influence diabetic bone metabolism [20]. The decrease bone formation and inadequate accrual peak bone mass in children with prepubertal onset T1DM has been proposed as a major contributing factor for low bone strength and osteoporosis in later life [23]. Men with T1DM tend to be particularly prone to osteopenia or osteoporosis compared to women of similar ages $[15,24,25]$ Estrogen adequacy and/or use of estrogen based oral contraceptive pills might be the reason for higher bone mass in women compared to men [25-26]. Furthermore, hypogonadism is quite common in men with T1DM and that may contribute to osteoporosis in males $[27,28]$. Another factor which may influence the BMD is body mass index (BMI). Studies have shown that lower BMI is associated with higher incidence of osteoporosis. The adipose tissue, apart from providing mechanical loading, also increases BMD through the activity of adipocytokines. Patients with TIDM also have a negative calcium balance as a result of hypercalciuria during 
periods of hyperglycemia, functional hypoparathyroidism, vitamin D deficiency and alterations in vitamin D metabolism [29-31]. In concordance with our results, duration of diabetes seems to play a key role given the lower BMD found among patients who have had diabetes for $>5$ years. In the Iowa Women's Health Study, women with type 1 diabetes were 12.25 times more likely to report having had a fracture compared to women without diabetes [10]. A low BMI as shown in our study is associated the increased possibility of osteoporosis [32]. Overweight and obesity are believed to be protective factors of BMD [33,34]. Obesity is strongly associated with higher BMD probably through mechanical loading and hormonal factors including insulin, estragon, and leptin [35] In conclusion, our findings demonstrate high frequency of osteoporosis in young women with type 1 diabetes. Although bone density testing is not routinely performed in young women, these data suggest that screening may be important in young women with type 1 diabetes. In addition, these women should be counseled regarding lifestyle interventions that may improve bone health, including adequate intake of calcium and vitamin D, and exercise Table 1.

Table 1: Characteristics of patients with type 1 diabetes mellitus stratified by presence of Osteoporosis.

\begin{tabular}{|c|c|c|c|c|}
\hline \multirow{2}{*}{ Parameters } & \multirow{2}{*}{ Total } & \multicolumn{2}{|c|}{ Osteoporosis } & \multirow{2}{*}{$P$ value } \\
\hline & & Yes & No & \\
\hline $\mathrm{n}(\%)$ & 137 & $53(38.7)$ & $84(61.3)$ & \\
\hline Age (years) & $19.1 \pm 4.9$ & $18.0 \pm 4.4$ & $19.9 \pm 5.0$ & 0.03 \\
\hline Duration of diabetes (years) & $6.7 \pm 5.0$ & $7.8 \pm 5.6$ & $5.7 \pm 4.2$ & 0.03 \\
\hline Body mass index $\left(\mathrm{kg} / \mathrm{m}^{2}\right)$ & $17.8 \pm 4.4$ & $15.5 \pm 3.2$ & $19.3 \pm 4.4$ & $<0.0001$ \\
\hline Height $(\mathrm{cm})$ & $159.3 \pm 10.3$ & $154.5 \pm 9.9$ & $162.3 \pm 9.3$ & $<0.0001$ \\
\hline $\mathrm{HbA1c}$ & $9.3 \pm 2.4$ & $9.8 \pm 2.6$ & $9.0 \pm 2.1$ & 0.04 \\
\hline 25-hydroxyvitamin D & $30.5 \pm 11.2$ & $28.9 \pm 10.0$ & $31.3 \pm 11.8$ & 0.3 \\
\hline Total serum calcium (mmol/l) [2.15-2.55] & $2.3 \pm 0.2$ & $2.3 \pm 0.2$ & $2.3 \pm 0.1$ & 0.5 \\
\hline Serum albumin (g/l) [34-52] & $43.3 \pm 3.8$ & $43.4 \pm 4.1$ & $43.3 \pm 3.6$ & 0.9 \\
\hline Phosphate(mmol/L) [0.74-1.2] & $1.3 \pm 0.3$ & $9.8 \pm 2.6$ & $9.0 \pm 2.1$ & 0.3 \\
\hline Alkaline phosphotase (U/L) & $149.7 \pm 103.9$ & $191.5 \pm 125.6$ & $122.6 \pm 76.2$ & $<0.0001$ \\
\hline Parathyroid hormones & $6.1 \pm 5.1$ & $7.3 \pm 7.4$ & $5.4 \pm 2.7$ & 0.04 \\
\hline
\end{tabular}

\section{Acknowledgment}

We are grateful to the staffs from the diabetic centre at King Fahad Armed Forces Hospital for his valuable contributions in data collection. The authors have no conflict of interest to disclose.

\section{References}

1. Classification and Diagnosis of Diabetes: Standards of Medical Care in Diabetes-2018. Diabetes Care (Supple 1): S13-S27.

2. King H, Rewers M (1993) Global estimates for the prevalence of diabetes mellitas and impaired glucose tolerante in adults. Diabetes care 16(1): 157-177.

3. El-Hazmi MA, Warsy AS, Al-Swailem AR, Al-Swailem AM, Sulaimani R (1996) Diabetes mellitus and impaired glucose tolerance in Saudi Arabia. Ann Saudi Med 16(4): 381-385.

4. Lampropoulos CE, Papaioannou I, D Cruz DP (2012) Osteoporosis a risk factor for cardiovascular disease? Nat Rev Rheumatol 8(10): 587-598.

5. Chen HL, Deng LL, Li JF (2013) Prevalence of osteoporosis and its associated factors among older men with type 2 diabetes. Int J Endocrinol p. 9.

6. Khoshhal KI (2011) Childhood osteoporosis. J Taibah Univ Med Sci 6(2): 61-66.

7. Kemink SA, Hermus AR, Swinkels LM, Lutterman JA, Smals (2000) AG: Osteopenia in insulin-dependent diabetes mellitus; prevalenceand aspects of pathophysiology. J Endocrinol Invest 23(5): 295-303.
8. Christensen J, Svendsen (1999) Bone mineral in pre- and postmenopausal women with insulin-dependent and non-insulin dependent diabetes mellitus. Osteoporos Int 10(4): 307-311.

9. Inzerillo A, Epstein S (2004) Osteoporosis and diabetes mellitus. Rev Endocr Metab Disord5: 261-268.

10. Forsen L, Meyer HE, Midthjell K, Edna TH (1999) Diabetes mellitus and the incidence of hip fracture: results from the Nord-Trondelag Health Survey. Diabetologia 42(8): 920-925.

11. Nicodemus K, Folsom A (2001) Type 1 and type 2 diabetes and incident hip fractures in postmenopausal women. Diabetes Car 24(7): 11921197.

12. Gunczler P, Lanes R, Paoli M, Martinis R, Villaroel O, et al. (2001) Decreased bone mineral density and bone formation markers shortly after diagnosis of clinical type 1 diabetes mellitus. J Pediatr Endocrinol 14: 525-528.

13. Liu EY, Wactawski-Wende J, Donahue RP, Dmochowski J, Hovey KM, (2003) Does low bone mineral density start in post-teenage years in women with type 1 diabetes? Diabetes Care 26(8): 2365-2369.

14. Valerio G, del Puente A, Buono P, Esposito A, Zanatta M (2004) Quantitative ultrasound of proximal phalanxes in patients with type 1 diabetes mellitus. Diabetes Res Clin Pract 64(3): 161-166.

15. Tuominen JT, Impivaara O, Puukka P, Connemara T (1999) Bone mineral density in patients with type 1 and type 2 diabetes. Diabetes Care 22(7): 1196-2000.

16. Kemink SA, Hermus AR, Swinkels LM, Lutterman JA, Smals AG (2000) Osteopenia in insulin-dependent diabetes mellitus: prevalence and aspects of pathophysiology. J Endocrinol Invest 23(5): 295-303. 
17. Hampson G, Evans C, Petitt RJ, Evans WD, Woodhead SJ, et al. (1998) Bone mineral density, collagen type 1 alpha 1 genotypes and bone turnover in premenopausal women with diabetes mellitus. Diabetologia 41(11): 1314-1320.

18. Vestergaard P (2007) Discrepancies in bone mineral density and fracture risk in patients with type 1 and type 2 diabetes: A metaanalysis. Osteoporos Int 18(4): 427-444.

19. Joshi A, Varthakavi P, Chadha M, Bhagwat N (2013) A study of bone mineral density and its determinants in type 1 diabetes. J Osteoporos 397-814.

20. MunozTorres M, Jodar E, EscobarJimenez F, LopezIbarra PJ, Luna JD (1996) Bone mineral density measured by dual Xray absorptiometry in Spanish patients with insulin dependent diabetes mellitus. Calcif Tissue Int 58(5): 31-39.

21. Bouillon R (1991) Diabetic bone disease. Calcif Tissue Int 49(3): 155160.

22. McNair P, Madsbad S, Christiansen C, Christensen MS, Faber OK, et al. (1979) Bone loss in diabetes: effects of metabolic state. Diabetologia 17: 283-286.

23. Rejnmark L, Vestergaard P, Heickendorff L, Andreasen F, Mosekilala $\mathrm{L}$ (2006) Loop diuretics increase bone turnover and decrease BMD in osteopenic postmenopausal women: Results from a randomized controlled study with bumetanide. J Bone Miner Res 21(1): 163170

24. Roggen I, Gies I, Vanbesien J, Louis O, De Schepper J (2013) Trabecular bone mineral density and bone geometry of the distal radius at completion of pubertal growth in childhood type 1 diabetes. Horm Res Paediatr 79(2): 68-74.

25. Hamilton EJ, Rakic V, Davis WA, Paul Chubb SA, Kamber N, et al. (2012) A fiveyear prospective study of bone mineral densityin men and women with diabetes: The Fremantle Diabetes Study. Acta Diabetol 49: 153-158.

26. Hadjidakis DJ, Raptis AE, Sfakianakis M, Mylonakis A, Raptis SA (2006) Bone mineral density of both genders in Type 1 diabetes according to bone composition. J Diabetes Complications 20(5): 302-307.
27. Lunt H, Florkowski CM, Cundy T, Kendall D, Brown LJ, et al. (1998) A populationbased study of bone mineral density in women with longstanding type 1 (insulin dependent) diabetes. Diabetes Res Clin Pract 40: 3138.

28. LopezAlvarenga JC, Zariñán T, Olivares A, GonzalezBarranco J, Veldhuis JD, et al. (2000) Poorly controlled type I diabetes mellitus in young men selectively suppresses luteinizing hormone secretory burst mass. J Clin Endocrinol Metab 87(12): 5507-5515.

29. Orwoll ES, Klein RF (1995) Osteoporosis in men. Endocr Rev 16(1): 87116.

30. Thalassinos NC, Hadjiyanni P, Tzanela M, Alevizaki C, Philokiprou D (1993) Calcium metabolism in diabetes mellitus: Effect of improved blood glucose control. Diabet Med 10(4): 341344.

31. Daga RA, Laway BA, Shah ZA, Mir SA, Kotwal SK, et al. (2012) High prevalence of vitamin D deficiency among newly diagnosed youthonset diabetes mellitus in north India. Arq Bras Endocrinol Metabol 56: 423428 .

32. Borkar VV, Devidayal, Verma S, Bhalla AK (2010) Low levels of vitamin D in North Indian children with newly diagnosed type 1 diabetes. Pediatr Diabetes 11: 345-350.

33. Espallargues M, Sampietro-Colom L, Estrada M (2001) Identifying bone-mass-related risk factors for fracture to guide bone densitometry measurements: a systematic review of the literature. Osteoporosis International 12(10): 811-822.

34. Wang ML, Bachrach KM, Loan M, Hudes M, Flegal K, et al. (2005) The relative contributions of lean tissue mass and fat mass to bone density in young women. Bone37(4): 474-481.

35. Barrera G, Bunout D, Gattas V, Maza V, Leiva L, et al. (2004) A high body mass index protects against femoral neck osteoporosis in healthy elderly subjects. Nutrition 20(9): 769-771.

36. Felson D, Zhang Y, Hannan M, Anderson J (1993) Effects of weight and body mass index on bone mineral density in men and women: the Framingham Study. J Bone Miner Res 8(5): 567-573.

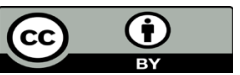

This work is licensed under Creative Commons Attribution 4.0 License

To Submit Your Article Click Here:

Submit Article

DOI: $10.32474 / A D 0.2018 .01 .000114$

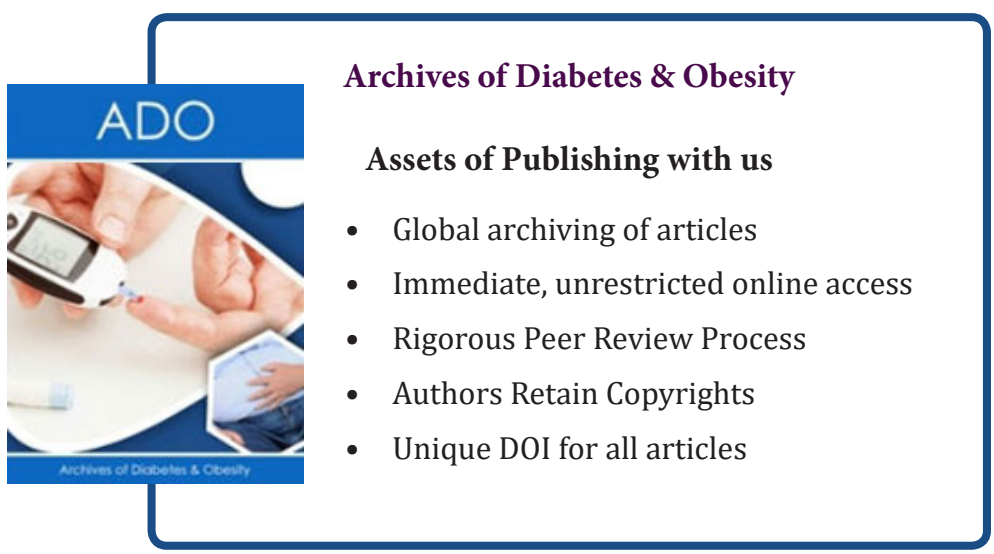

